\title{
Interactions of Phosphorus with Anthropogenic and Engineered Particulate Matter as a Function of Mass, Number and Surface Area
}

\author{
Jong-Yeop Kim, Jia Ma, Kim Howerter, Giuseppina Garofalo \\ and John Sansalone
}

Particulate matter (PM) is ubiquitous in modern urban environments, generated by most anthropogenic activities. Traffic activities, for example, generate significant loads of PM, as do land-disturbing and construction activities. There are also significant sources of biogenic particulate loads in the modern urban environment, such as vegetation. While the ubiquity of PM is generally recognized, the sources, characteristics, transport, treatment and impact of particulate matter in urban runoff (rainfall or snow) continue to be the subject of lively debate. Such knowledge is fundamentally important for modeling urban runoff particulates, particularly regarding the transport and fate of chemicals such as phosphorus and metals. As modeling capabilities begin to couple hydrology, chemistry and PM, improved models such as the USEPA stormwater management model (SWMM) require defensible data and algorithms. Three common topics of debate and new experimental results are presented.

The first concerns particle size distributions (PSDs) in urban runoff. Despite advances in knowledge of PSDs, the sampling and examination of runoff has not significantly changed in practice. Such knowledge should significantly impact model development, the design and performance of best

Kim, J., J. Ma, K.M. Howerter, G. Garofalo and J. Sansalone. 2008. "Interactions of Phosphorus with Anthropogenic and Engineered Particulate Matter as a Function of Mass, Number and Surface Area." Journal of Water Management Modeling R228-01. doi: 10.14796/JWMM.R228-01.

(C) CHI 2008 www.chijournal.org ISSN: 2292-6062 (Formerly in Reliable Modeling of Urban Water Systems. ISBN: 978-0-9808853-0-9) 
management practices (BMPs) and municipal separate storm sewer systems (MS4). Suspended and colloidal particulates are ecologically and environmentally important as well as acutely bio-available. Sediment and debris size particles represent both a significant load for MS4 and maintenance liability for BMPs that is not accounted for by traditional total suspended solids (TSS). Our measurements, models, treatment and regulations would be well-served by accounting for a wide spectrum of PSDs, despite the additional complexity. This will provide a foundation for BMP numerical effluent limits, monitoring and inventory requirements in MS4s, as well as accurate and quantifiable total maximum daily loads (TMDLs).

The second topic is that of surface area (SA) and pollutant distribution (the focus herein being phosphorus) as a function of granulometry (for example, PSDs) and how SA (units of area $\mathrm{L}^{2}$ ) relates to the transport and fate of phosphorus. In large part, this debate can be resolved with knowledge of the actual PSD on a gravimetric basis (units of mass M) at a particular location in the watershed or BMP, and knowledge of a normalized quantity that is known as specific surface area (SSA) with units of $\mathrm{L}^{2} / \mathrm{M}$ (area/mass). By definition, SSA increases with decreasing particle size; yet depending on the gravimetric PSD, total SA can be predominately in the sediment fraction of source area runoff.

The third topic is a quantitative example of the wide disparity between engineered particulate media surface behavior with respect to the fate of phosphorus. Common media, such as perlite, used in stormwater filtration have very little ability to sorb phosphorus in stormwater. This can largely be shown to be a function of available SA, surface charge and species competition. Equilibria, kinetics, breakthrough and desorption are quantifiable phenomena.

\subsection{Introduction}

Urban anthropogenic activities result in hydrologic and hydraulic modifications in the built urban environment. More effective and rapid conveyance in urban surfaces and drainage systems has resulted in increased peak discharges and increased entrainment of PM from impervious surfaces (Bedient and Huber 1992). These improved hydraulic characteristics of urban surfaces transport a wide gradation of PM ranging in size from sub-micron $(<1 \mu \mathrm{m})$ to greater than 10,000 $\mu \mathrm{m}$ (Sansalone et al. 1998) in 
concentrations with an order of magnitude or more compared to the predeveloped natural environment (Viessman and Lewis 1996).

PM is ubiquitous in the urban environment, generated by activities that are part of our daily routines. For example, traffic activities including abrasive interaction of tires against pavement, and vehicular part abrasion are sources of particulate constituents in urban storm runoff from the paved urban surface (Muschack 1990). Construction of urban infrastructure also generates a significant source of PM. PM in rainfall-runoff from urban land uses is also a potential reservoir for both chemical constituents including metals, organics and phosphorus and toxicity (Gjessing et al. 1984). Studies on 541 streambed-sediment samples collected across the United States showed that $49 \%$ of the sites sampled in urban settings had concentrations of one or more trace metal elements that exceeded levels at which adverse effects could occur in aquatic biota (Rice 1999). The loadings and concentrations of suspended solids, nutrients and other contaminants can be much higher in urban runoff than in runoff from unimpaired and rural areas (Sartor and Boyd, 1972).

The granulometric characteristics of PM can significantly affect hydrodynamic transport, particulate-solute interaction, and eventual fate of both the anthropogenic particulate constituents and solute. Knowledge of such granulometry is critical to accurately assessing the impact of stormwater pollution on drainage waterways and receiving waters and to designing methods for minimizing the impacts. Granulometry parameters important to runoff treatment include mass loading, particle gradation indices such as $d_{50}$, particle size indices such as number volume mean size $\left(1_{\text {nv }}\right)$, particle density $\left(\rho_{\mathrm{s}}\right)$, specific surface area (SSA), surface area (SA), particle count $\left(\mathrm{N}_{\mathrm{t}}\right)$, and PM as sediment-suspended concentration (SSC).

\subsubsection{Particle Size Distribution in Urban Surface and Runoff}

Stormwater PSDs are commonly reported on a dry mass basis. For example, early information on PSD and associated pollutants was reported by Sartor and Boyd (1972). In their studies of gravimetric-based PSDs of dry particles deposited on pavement surface, it was found that $15 \%$ of PM were less than $104 \mu \mathrm{m}, 28 \%$ were between 104-246 $\mu \mathrm{m}, 25 \%$ between 246 and $840 \mu \mathrm{m}$, $8 \%$ between 846 and $2,000 \mu \mathrm{m}$ and $24 \%$ larger than $2000 \mu \mathrm{m}$. Shaheen (1975) in a similar study found that about $58 \%$ of particles deposited on highways were larger than $250 \mu \mathrm{m}$. With respect to source area runoff, Sansalone et al. (1998) gravimetric-based PSD results indicated that 20\% of 
PM was from 600 to $1,000 \mu \mathrm{m}$ and $30 \%$ was from 1,000 to $10,000 \mu \mathrm{m}$. But these PSDs are significantly coarser than those reported by other studies (Ball and Abustan 1995, Jacopin et al. 1999). For example, the results of particle size distribution in the study (Ball and Abustan 1995) indicated that particles less than $100 \mu \mathrm{m}$ represented $70 \%$ to $92 \%$ of the total mass. Although the variation in particle size is influenced by site conditions, traffic volume, wind patterns, rainfall/runoff characteristics and the application of winter de-icing materials, inconsistent sampling methods, PSD analytical techniques, location of sampling in the watershed and initial PM entrainment contribute to such variation. Sampling from the entire cross-section of flow is critical to capture a full spectrum of PSDs in urban stormwater, because an inaccurate representation of non-point source pollution can result in the design of oversized measures with excessive capital costs and maintenance requirements or undersized and ineffective measures.

A clear understanding of the amount of pollutants associated with different particle size ranges is also fundamentally important to effective design of treatment facilities to target the most polluted particle sizes (Vaze and Chiew 2002). Most automatic samplers are, however, only capable of entraining the suspended and finer settleable fraction. These samplers cannot representatively sample the entire gradation of particles, especially sand (75$2000 \mu \mathrm{m})$ and gravel size particles $(>2000 \mu \mathrm{m})$ that settle rapidly. While being few in number, gravel size particles $(>2000 \mu \mathrm{m})$ could comprise up to $20 \%$ of particulate matter load (Sansalone et al. 1998), and represent a significant inventory on the urban surface and in conveyance systems.

In addition to the difficulties associated with proper sampling of the wide spectrum of PSDs in stormwater, a fundamental limitation of characterizing PSDs in stormwater runoff is that no single approach can characterize the entire range of particle sizes present. Although several researchers have measured PSDs in highway runoff or stormwater (Characklis and Wiesner 1997, Legret and Pagotto 1999, Westerlund and Viklander 2006), automatic samplers were used or sampling from full-cross sectional flow was rarely made. In addition, few researchers have counted PSD over an entire range of gradation from 1 to $>10,000 \mu \mathrm{m}$ and over an entire duration of storm event.

Defensible data of PSDs and particle concentration in runoff provided by proper sampling and analysis methods will be a critical component for the development of water quality monitoring programs as well as accurate and quantifiable TMDLs. While the finer suspended fraction is more bioavailable and mobile, the coarser fractions are a chronic urban inventory and load issue, while also providing a significant source for pollutant leaching in the urban surface and, in conveyance systems and in BMPs. 


\subsubsection{Surface Area (SA) and Phosphorus Distribution as a Function of Granulometry}

An analysis of source area stormwater PM indicates that although SSA does increase with decreasing particle diameter, a significant part of total SA is associated with the mid-range to coarse particle sizes $(200-800 \mu \mathrm{m})$ (Sansalone et al. 1998). This is a size range of particles where flocculation phenomenon between particles is not as significant as suspended range $(<25$ $\mu \mathrm{m})$. Interestingly, these results indicate the increase in SSA with decreasing particle size is not monotonically increasing as would be expected for solid spherical particles of constant particle density. Whether associated with anthropogenic urban particles or engineered sorptive media for the separation of dissolved constituents from stormwater, solid-water interfacial surface area is an important parameter. For example, it has been demonstrated that the distribution of heavy metal mass and particle (or media) surface area is strongly correlated (Sansalone and Tribouillard 1999).

Phosphorus is found to distribute across the PM gradation mobilized by rainfall-runoff. Ranging from 1 to $10,000 \mu \mathrm{m}$ in size, the ubiquitous particulates in stormwater can be operationally classified as sediment $(>75$ $\mu \mathrm{m})$, settleable $(75 \sim 25 \mu \mathrm{m})$ and suspended $(<\sim 25 \mu \mathrm{m})$ based on the 1 hour Imhoff settling test convention (Sansalone et al. 1998). Physical and chemical characteristics of PM (or sorptive media) combined with variable residence time, stochastic flow loading and changing aqueous conditions dictate the partitioning and distribution of phosphorus in stormwater.

Recognizing urban stormwater as a pronounced non-point source of phosphorus pollution, an understanding of the role that particulates play in

phosphorus fate and transport in urban stormwater is critical, yet the knowledge of constitutive relationships of phosphorus between constituents and constituent phases is still in urgent need. In the present study, total phosphorus distribution across the whole granular size range of particulate phases was characterized based on the phosphorus equilibrium partitioning between dissolved and particulate phases for each storm event studied. The granulometric distribution of phosphorus mass is a good indication of total surface area distribution across the entire particle size ranges.

\subsubsection{Engineered Media Surface Interactions with Phosphorus}

Engineered sorptive media for the filtration of stormwater have been applied under conditions where there is primary treatment; and in other less 
sustainable conditions where the media is directly loaded by stormwater. Because of the chemical and PM complexity of stormwater, applications of engineered sorptive media are successful applied as secondary or tertiary treatment with some form of separate or integral primary treatment.

Media for separation of phosphorus from stormwater have been of significant interest over the last several decades. A variety of adsorbents including silica sand and engineered media have been investigated for phosphorus adsorption. This chapter examines the behavior of these two media, perlite commercially used in stormwater filters, and aluminum oxide coated media (AOCM). Physically, both test media have similar diameters (3-6 $\mathrm{mm}$ ) and high total system porosity (including media porosity) $>0.7$. However, AOCM have the combination of high specific surface area (250$300 \mathrm{~m}^{2} / \mathrm{g}$ ) and high surface charge as compared to perlite, a much more friable media. It was hypothesized that the different physical and chemical properties of both media would result in a significant difference in behavior with respect to phosphorus. The surface chemistry of AOCM is designed to selectively bind the phosphorus anions into the media matrix, permitting mass transfer from stormwater. Adsorption onto AOCM includes physical and chemical mechanisms. Both mechanisms can have rapid kinetics; several minutes. Longer term removal of phosphorus from solution has been attributed to chemically adsorbed phosphorus, the diffusion of the externally adsorbed phosphorus to engineered sites inside the matrix, and the precipitation of crystalline Al phosphates. Numerous studies have been carried out in an attempt to develop and assess adsorbent data for phosphorus removal. The major problem is that only scattered fixed-bed data is available and most data are based only on batch equilibria without an examination of kinetics, breakthrough or chemistry. The direct application of batch isotherm data must be combined with these additional analyses. The extent of adsorption in flow through adsorption is dependent of diffusion, flow regimes and contacting patterns. Lab-scale breakthrough adsorption tests are an essential precursor to a full-scale design. In this study, the surface properties of AOCM were examined and compared with perlite.

\subsection{Methodology}

\subsubsection{Experimental Site and Runoff Sampling}

An urban pavement watershed $\left(1088 \mathrm{~m}^{2}\right)$ was selected as representative of source area runoff in urban Baton Rouge, Louisiana to examine transport 
and size distributions of particulate matter in urban highway runoff. The pavement surface is Portland cement concrete (PCC) and has a tangential slope of $2.02 \%$. Site characteristics are detailed elsewhere (Dean et al. 2005). All of the runoff generated from the watershed of east and west bound lanes were combined and flowed through a 2 inch Parshall flume, influent sampling drop box, a hydrodynamic separator, and finally discharged into two 1000-gallon storage tanks. A $90 \mathrm{~cm}$ diameter hydrodynamic separator (volume $\approx 420 \mathrm{~L}$ ) was installed to capture coarse particles in runoff from the source area throughout the entire duration of storm event. Flow rates were measured with the 2 inch Parshall flume.

Storm events occurring between March 14, 2004 and October 03, 2005 were monitored. 14-17 influent and 13-15 effluent discrete samples were taken in duplicates depending on the duration of each event with the exception of the October 3, 2005 event. At each sampling time, replicate $12 \mathrm{~L}$, and $1 \mathrm{~L}$ samples were manually taken from influent and effluent flow using wide-mouth polypropylene containers. $12 \mathrm{~L}$ samples were used to recover sediment fraction $(>75 \mu \mathrm{m})$ and $1 \mathrm{~L}$ samples were used for the measurement of settleable $(75 \sim 25 \mu \mathrm{m})$ and suspended particles $(1 \sim 25 \mu \mathrm{m})$ concentrations. To ensure sampling from the entire cross sectional area of flow, all influent and effluent samples were collected manually from free falls as runoff exited the Parshall flume and effluent pipe, respectively. Sampling methods are detailed elsewhere (Dean et al. 2005).

\subsubsection{Particle Fraction Analyses}

Three particle fractions (suspended, settleable, and sediment) were analyzed separately for each replicate influent sample. Dry sieving methods have been commonly used for the separation and fractionation of particles (Allen 2004). In this case, wet sieving was applied to separate sediment $(>75-\mu \mathrm{m})$ from each discrete rainfall runoff sample in the 1-L and 12-L containers. After sediment fraction was recovered from the 1-L samples, settleable (25 $75-\mu \mathrm{m})$ and suspended $(<\sim 25-\mu \mathrm{m})$ particles were separated by the standard Imhoff Cone protocol. Particles settled in the Imhoff cone were defined as settleable particles, and suspended particles were those which remained on a nominal $1 \mu \mathrm{m}$ glass fiber filter. Table 1.1 describes the nominal size range and analysis method of each particle fraction. Methods include ASTM and Standard Method protocols. 
Table 1.1 Particle fractions, corresponding nominal size range and separation analysis methodology in stormwater runoff.

\begin{tabular}{|c|c|c|c|}
\hline & Particle fraction & Nominal size range & Operational Separation Analysis \\
\hline \multirow[t]{3}{*}{  } & $\begin{array}{l}\text { Suspended particles } \\
\text { (Non settleable } \\
\text { particles) }\end{array}$ & 1 to $\sim 25 \mu \mathrm{m}$ & $\begin{array}{l}\text { Particles remaining in suspension after } \\
1 \text { hour of quiescent settling in an } \\
\text { Imhoff cone (Method } 2540 \mathrm{~F} \text { in APHA } \\
\text { 1998) is filtered through } 1 \mu \mathrm{m} \text { fiber } \\
\text { glass filter (Method } 2540 \mathrm{D} \text { in APHA } \\
1998 \text { ) }\end{array}$ \\
\hline & Settleable particles & $\sim 25$ to $75 \mu \mathrm{m}$ & $\begin{array}{l}\text { Settled particles after } 1 \text { hour of } \\
\text { quiescent settling in an Imhoff cone. } \\
\text { (Method 2540F in APHA 1998) }\end{array}$ \\
\hline & Sediment particles & larger than $75 \mu \mathrm{m}$ & $\begin{array}{l}\text { Particles remaining on the } \# 200 \text { sieve } \\
\text { (ASTM D422 1993) }\end{array}$ \\
\hline
\end{tabular}

\subsubsection{Particle Size Distributions}

After each event, all PM was recovered as wet slurry and transported to the lab for air-drying at $40^{\circ} \mathrm{C}$. Once dried, all $\mathrm{PM}$ was carefully disaggregated with a rubber-tipped pestle and mortar and mechanical sieve analysis was performed to obtain the influent PSD $>75 \mu \mathrm{m}$ by following the modified procedure ASTM D422 (ASTM 1993, Sansalone et al 1998).

Since no single PSD analytical technology can characterize a wide range of particle sizes from clay-size to gravel-size; a laser diffraction type of particle analyzer was used to analyze the particle size distribution for the effluent discrete samples. While the measurable size range of the laser analyzer covers from 1 to $250 \mu \mathrm{m}$, the laser results were restricted to the range of 1 to $75 \mu \mathrm{m}$ to complement the mechanical sieve data. Influent particle gradation for each event was then calculated by the mass weighted summation of PSDs from the captured and effluent particles. This methodology ensures the characterization of the entire spectrum of influent PSD. As with any BMP analysis, total measured mass of captured and effluent PM load particles is required to be within $10 \%$ of influent mass load to ensure mass conservation and QA/QC. This two-part methodology of dry mechanical sieve analysis and wet laser diffraction analysis is based on the differing characteristics of each size range (fine vs. coarse, separated at 75 $\mu \mathrm{m})$ and has a direct parallel to experimental methods in soil mechanics. Given the low volatile fraction $(<30 \%)$ and low clay-size content of the PM $(<1 \%)$ and the inorganic granular nature of the PM, the source area gradation represents a hetero-disperse granular material. 


\subsubsection{Particulate-bound Phosphorus Analysis}

Since there are no regulatory approved or standardized methods for measuring particulate-bound phosphorus (PP) in urban stormwater, currently employed methods used for soil, solid waste, and wastewater quality analyses (APHA 1998) are adapted for the measurement of PP in the present study. PP concentration $[\mathrm{mg} / \mathrm{g}]$ was measured over the entire granulometric size of particles captured in HS. The measurement of particle-bound phosphorus in highway runoff involves three steps: (i) mechanical sieve analysis for PSD of influent particles ranging from $<25 \mu \mathrm{m}$ to $>9500 \mu \mathrm{m}$ (maximum total 17 gradations), record the corresponding mass for each gradation and ready for TP analysis; (ii) acid digestion and conversion of particulate bound phosphorus to dissolved phosphate; and (iii) analytical measurement of the dissolved phosphate using colorimetric reagent. A persulfate digestion was used to convert any other forms of phosphorus to orthophosphate (Morton et al. 2003). Dissolved orthophosphate was measured by HACH DR/2000 Spectrophotometer using PhosVer 3 ascorbic acid method (APHA 1998)

\subsection{Results and Discussion}

\subsubsection{Particle Size Distributions (PSDs) in Urban Runoff}

Particles were collected in the hydrodynamic separator (HS) and in effluent flow on an event basis. Since the gradations of particles captured in the HS are mainly composed of coarse particles larger than $75 \mu \mathrm{m}$ up to larger than $10,000 \mu \mathrm{m}$, mechanical sieve analysis was performed to measure PSDs. Particles in effluent flow from the HS are typically in less than $150 \mu \mathrm{m}$ size range. Thus, a laser diffraction particle analyzer, measuring the size range of 1 to $250 \mu \mathrm{m}$, was used to examine PSDs in effluent flow.

Figure 1.1 shows the variability of representative cumulative PSDs for the particulate matter transported in runoff during eight storm events examined at the experimental site. Cumulative gamma distribution was used to model each PSD curve as a function of particle size with two parameters $(\varphi$ and $\eta)$. Granulometric indices and statistics for PM transported by each event are summarized in Table 1.2. 




\begin{tabular}{cccc}
\hline Particle size distributions (PSDs) & \multicolumn{2}{c}{ Model parameters } & \multirow{2}{*}{$\mathrm{R}^{2}$} \\
\cline { 2 - 3 } & $\eta$ & $\varphi$ & \\
Finest PSD (14 Oct 2004) & 156.7 & 0.63 & 0.97 \\
Coarsest PSD (21 Aug 2004) & 2665.6 & 0.45 & 0.95 \\
Median PSD & 686.9 & 0.54 & 0.96 \\
\hline
\end{tabular}

$\Gamma(x)=\int_{0}^{x} f(x) d x \quad$ In this expression, $f(x)$ represents dimensionless $f(x)=\frac{\left(\frac{x}{\eta}\right)^{\varphi-1} e^{\left(-\frac{x}{\eta}\right)}}{\eta \cdot \Gamma(\varphi)} \quad \begin{gathered}x \text { represents particle size }(\mu \mathrm{m}) ; \eta \text { is the scale factor }(\mu \mathrm{m}) \\ \text { and } \varphi \text { is the dimensionless shape factor. }\end{gathered}$

Figure 1.1 The range of particle size distributions (PSDs) modeled using cumulative gamma distribution for eight stormwater events from the source area in Baton Rouge, LA.

The average median diameter based on mass for the twelve events was $127 \mu \mathrm{m}$, corresponding to a $\Phi_{50}$ size of 3.34. Based on the interpretation for $\Phi_{50}$ (Nybakken 1998) in different ranges, results indicate that PM in stormwater runoff is similar in size to very fine sand. These PSDs illustrate 
that within a single event a wide range of particles from micron size to larger than $10,000 \mu \mathrm{m}$ are entrained and transported by urban runoff. Significant variability of event-based influent PSD was also observed between the events. PM transported by three events (April 24, August 20 and June 05) were coarser than the rest as illustrated in Table 1.2. Influent loads transported by the August 20 and June 05 events included $68 \%$ and $66 \%$ of sediment fraction, respectively. In contrast, $67 \%$ of influent particulate matter in the October 14 event was suspended particles while the sediment fraction constituted only $10 \%$ of the influent load. The PSDs of the March $14\left(\mathrm{~d}_{50 \mathrm{~m}}\right.$ of $\left.43 \mu \mathrm{m}\right)$ and October 14 event $\left(\mathrm{d}_{50 \mathrm{~m}}\right.$ of $\left.29 \mu \mathrm{m}\right)$ generated fine sizes of particles throughout the duration of event. While only $7 \%$ of particles entrained in runoff during the March 14 event was in such size range, $20 \sim 30 \%$ of overall influent particulate matter by mass were gravel size particles $(>2000 \mu \mathrm{m})$ for the April 24, August 20 and June 05 events.



$\underline{\text { 14-Mar-2004 }}$



05-Jun-2005



$\underline{\text { 24-Apr-2004 }}$



30-Jun-2005



$\underline{\text { 20-Aug-2004 }}$



$\underline{\text { 21-Aug-2005 }}$



14-Oct-2004



$\underline{\text { 03-Oct-2005 }}$

Sediment particle $(>75 \mu \mathrm{m})$

Settleable particle $(25 \sim 75 \mu \mathrm{m})$

Suspended particle $(1.2 \sim 25 \mu \mathrm{m})$

Figure 1.2 Influent load of three particulate matter fractions including sediment $(>75 \mu \mathrm{m})$, settleable $(\sim 25-75 \mu \mathrm{m})$ and suspended particles $(1 \sim 25 \mu \mathrm{m})$ transported in urban runoff. It should be noted that the $25 \mu \mathrm{m}$ is dependent on the specific gravity of the PM. 
PSD results in this study are similar to source area results by Sansalone et al. (1998) for urban pavement stormwater: $10-30 \%$ of particles in mass were larger than $1000 \mu \mathrm{m}$. Also, wide ranges in the PSDs measured from similar land uses have been reported by other researchers (Sartor and Boyd 1972, Shaheen 1975, Ellis and Revitt 1981, Vase and Chiew 2002). However, since PSDs in those studies were measured from surface sediments on impervious road, not particles entrained in runoff, their results are comparable only to the coarser side of the presented PSDs herein. In contrast, PSDs in a number of studies (Jacopin et al. 1990; Ball and Abustan 1995; Westerlund and Viklander 2006), where PSDs in runoff were examined, were much finer than the presented particle gradations. Observation of finer PSDs in these studies could indicate the settleablesediment fractions were separated upstream before reaching sampling locations. Results may also be attributed to the use of a tube-intake automatic sampler as a sampling method, and/or the inability to keep coarser PM entrained in the path of laser and the light scattering detector in an aqueous dispersion when coarser PM is analyzed with batch-type cells.

Table 1.2 Summary of statistical characteristics of particle size distribution for the influent and effluent particulate mass load of SHS unit at Baton Rouge site.

\begin{tabular}{|c|c|c|c|c|c|c|c|c|c|}
\hline $\begin{array}{l}\text { Rain/ } \\
\text { Runoff } \\
\text { Event }\end{array}$ & $\begin{array}{r}\mathrm{d}_{50 \mathrm{~m}} \\
(\mu \mathrm{m})\end{array}$ & $\Phi_{50}$ & $\begin{array}{c}d_{g} \\
(\mu \mathrm{m})\end{array}$ & $\begin{array}{r}\mathrm{d}_{10 \mathrm{~m}} \\
(\mu \mathrm{m} \\
)\end{array}$ & $\begin{array}{l}d_{25 \mathrm{~m}} \\
(\mu \mathrm{m})\end{array}$ & $\begin{array}{l}d_{75 \mathrm{~m}} \\
(\mu \mathrm{m})\end{array}$ & $\begin{array}{l}d_{90 m} \\
(\mu \mathrm{m})\end{array}$ & $\begin{array}{l}\text { Central } \\
\text { Tendency }\end{array}$ & $\begin{array}{c}\text { Mass } \\
\text { load } \\
(\mathrm{g})\end{array}$ \\
\hline \multicolumn{10}{|c|}{ INFLUENT particle size distribution } \\
\hline 14-Mar-04 & 43 & 4.53 & 54 & 7 & 17 & 171 & 416 & Silt & 4949 \\
\hline 24-Apr-04 & 233 & 2.10 & 269 & 17 & 52 & 1023 & 3702 & fine sand & 3219 \\
\hline 20-Aug-04 & 300 & 1.74 & 440 & 22 & 65 & 2548 & 8478 & $\begin{array}{l}\text { medium } \\
\text { sand }\end{array}$ & 10591 \\
\hline 14-Oct-04 & 29 & 5.08 & 32 & 6 & 11 & 69 & 466 & Silt & 544 \\
\hline 5-Jun-05 & 247 & 2.02 & 418 & 25 & 57 & 2349 & 6949 & fine sand & 4758 \\
\hline 30-Jun-05 & 69 & 3.85 & 103 & 12 & 32 & 265 & 1501 & $\begin{array}{l}\text { very fine } \\
\text { sand }\end{array}$ & 4044 \\
\hline 21-Aug-05 & 106 & 3.23 & 162 & 13 & 36 & 394 & 3768 & $\begin{array}{l}\text { very fine } \\
\text { sand }\end{array}$ & 8733 \\
\hline 3 -Oct-05 & 58 & 4.12 & 79 & 8 & 22 & 223 & 1734 & Silt & 739 \\
\hline Mean & 127 & 3.34 & 186 & 14 & 37 & 895 & 3377 & $\begin{array}{l}\text { very fine } \\
\text { sand }\end{array}$ & 4697 \\
\hline Std. dev. & 98 & 1.08 & 157 & 7 & 19 & 999 & 2988 & & 3518 \\
\hline
\end{tabular}


The significant percentages of sand and gravel size particles in influent runoff flow emphasize the importance of proper sampling and analysis methodology to correctly quantify PM concentration, which is in turn used for the calculation of mass load by integrating with flow rate.

Compositions of influent loads transported in urban runoff are illustrated in Figure 1.2 based on three PM fractions (sediment, settleable and suspended particles). Sediments in urban runoff originate primarily from PM deposited on impervious areas (Sharpin 1995). Thus, there is a general concept that if sediments on the same catchment area are transported by a higher intensity event with similar previous dry hours, coarser particle size distributions might be expected. While this concept may be generally applicable, the results in Figure 1.2 demonstrate that it is not always true. For example, although both of the mean $\left(\mathrm{Q}_{\text {mean }}\right)$ and peak $\left(\mathrm{Q}_{\text {peak }}\right)$ runoff flow from the October 03 event were higher than those from the June 05 event as indicated in Table 1.3, influent load from the June 05 event contains a higher percentage of sediment fraction than the October 03 event.

Table 1.3 Summary of hydrologic, sampling based indices for 8 events analyzed for the $\mathrm{I}-10$ experimental catchment $\left(1088-\mathrm{m}^{2}\right)$.

\begin{tabular}{|c|c|c|c|c|c|c|c|}
\hline \multirow[b]{2}{*}{$\begin{array}{c}\text { Rainfall } \\
\text { Runoff } \\
\text { Event }\end{array}$} & \multicolumn{7}{|c|}{ Hydrologic, and Sampling Based Indices for Rainfall-runoff event } \\
\hline & $\begin{array}{l}\mathrm{PDH}^{1} \\
(\mathrm{hrs})\end{array}$ & $\begin{array}{c}\text { Rainfall } \\
\text { Duration } \\
(\min )\end{array}$ & $\begin{array}{l}\text { Total } \\
\text { Precip. } \\
(\mathrm{mm})\end{array}$ & $\begin{array}{l}\text { Runoff } \\
\text { Volume } \\
\text { (L) }\end{array}$ & $\begin{array}{l}\mathrm{Q}_{\text {mean }} \\
(\mathrm{L} / \mathrm{s})\end{array}$ & $\begin{array}{l}Q_{\text {peak }} \\
(\mathrm{L} / \mathrm{s})\end{array}$ & $\begin{array}{c}\mathrm{t}_{\mathrm{p}}{ }^{2} \\
(\mathrm{~min})\end{array}$ \\
\hline 14-Mar-04 & 204 & 413 & 26.2 & 24076 & 1 & 6.4 & 295 \\
\hline 24-Apr-04 & 313 & 184 & 7.2 & 7288 & 0.6 & 1.8 & 116 \\
\hline 20-Aug-04 & 26 & 30 & 17.3 & 12286 & 5.1 & 17.5 & 23 \\
\hline $14-$ Oct-04 & 84 & 180 & 2.6 & 1672 & 0.1 & 0.6 & 60 \\
\hline 5-Jun-05 & 117 & 52 & 7.1 & 5856 & 1.9 & 9.4 & 7 \\
\hline 30-Jun-05 & 143 & 79 & 19.1 & 15117 & 3.6 & 13.8 & 11 \\
\hline 21-Aug-05 & 94 & 113 & 51.1 & 50002 & 7.9 & 17.3 & 29 \\
\hline $3-O c t-05$ & 217 & 10 & 3.3 & 2615 & 3.1 & 12.1 & 3 \\
\hline \multicolumn{8}{|c|}{ Statistics for the Rainfall-Runoff Events } \\
\hline Mean & 150 & 133 & 16.7 & 14864 & 2.9 & 9.8 & 68 \\
\hline Median & 130 & 96 & 12.3 & 9787 & 2.5 & 10.7 & 26 \\
\hline $\mathrm{SD}^{3}$ & 91 & 130 & 16.2 & 15986 & 2.6 & 6.5 & 99 \\
\hline $\begin{array}{l}\text { Note: } 1 . \mathrm{P} \\
\text { last event } \\
\text { 2. } \mathrm{t}_{\mathrm{p}} \text { : The } \\
\text { event } \\
\text { 3. SD Stan }\end{array}$ & $\begin{array}{l}\text { Prev } \\
\text { iccun } \\
\text { span }\end{array}$ & $\begin{array}{l}\text { us dry hol } \\
\text { ated at le } \\
\text { g betwee }\end{array}$ & $\begin{array}{l}\text { Time } \\
.02 \mathrm{inc} \\
\text { art of e }\end{array}$ & $\begin{array}{l}\text { g betwe } \\
\text { rainfall. } \\
\text { e runoff }\end{array}$ & $\mathrm{eecu}$ & ven & the \\
\hline
\end{tabular}




\subsubsection{Surface Area (SA) and Phosphorus Distribution as a Function of Granulometry}

The results of particulate-bound mass concentration illustrated in Figure 1.3 demonstrate that particulate phosphorus concentration generally increases with decreasing particle size. This would be expected, given that solid-phase concentration is normalized to particulate mass which decreases with smaller particle size. Particulate phosphorus concentration, i.e. phosphorus content per particle mass in each gradation, $[\mathrm{mg} / \mathrm{g}]$, ranged from $1.1 \sim 3.4$ regardless of the hydrograph. Results indicate that PP concentration is in part a function of the source area runoff, watershed, climate and loadings.


Figure 1.3 Particulate-bound phosphorus (PP) mass concentration over the wide gradation of particulate matter in urban stormwater

Granulometric distributions of PP across the entire particle range in Figure 1.4 demonstrate that, while phosphorus associated with suspended particles $(<\sim 25 \mu \mathrm{m})$ comprises a significant portion of PP in mass for all 
events, phosphorus associated with sediment particles $(>75 \mu \mathrm{m})$ constitute $60 \sim 64 \%$ of particulate-bound phosphorus for 24 April 2004 and 20 August 2004 events. For those events (14-Oct-2004 and 14-Mar-04) exhibiting fine influent particle gradations, total phosphorus mass associated with sediments was less than $35 \%$. Recognizing the previous finding that the distribution of metal mass and particle surface area (SA) is highly correlated (Sansalone and Tribouillard 1999), SA distributions of particulate matter are expected to be similar to the results of PP mass distributions presented in Figure 1.4.


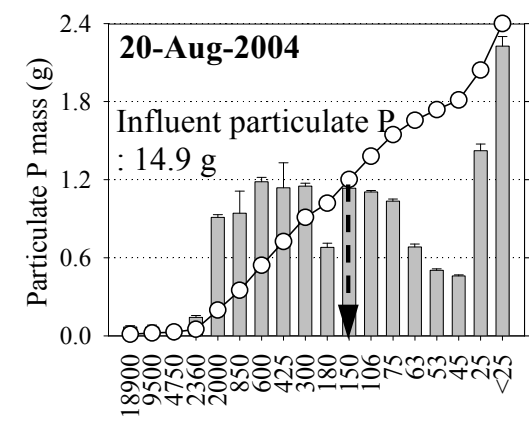

Particle Diameter $(\mu \mathrm{m})$



Particle Diameter $(\mu \mathrm{m})$

Figure 1.4 Particulate-bound phosphorus (PP) mass distribution as a function of particle size.

\subsubsection{Surface interactions of engineered media with phosphorus}

Results of media performance with respect to total dissolved phosphorus (TDP) are illustrated in Figure 1.5. These results clearly illustrate that media engineered for phosphorus adsorption have significant equilibrium capacity. In contrast, media such as perlite have very low phosphorus equilibrium adsorption capacity. These results are illustrated in plot (a) of Figure 1.5 and 
the aluminum oxide coated media (AOCM) equilibrium results can be predicted using a Freundlich isotherm model. Kinetics results are compared in plot (b) and the AOCM results clearly illustrate more much rapid adsorption kinetics as compared to perlite kinetics. The AOCM behavior can be predicted by second order kinetics.

The trajectory for breakthrough $\left(\mathrm{C} / \mathrm{C}_{0}=0.1\right)$ of TDP from the media and exhaustion $\left(\mathrm{C} / \mathrm{C}_{0}=0.9\right)$ of media TDP capacity are illustrated as part of the breakthrough curve as a function of the number of media bed volumes (total volume of media bed), $\mathrm{N}_{\mathrm{BV}}$ treated in plot (c). Results clearly indicate that AOCM has significant breakthrough and exhaustion capacity in terms of volume treated and that perlite has essentially no capacity for phosphorus, with nearly instantaneous breakthrough. An analytical breakthrough model was used to predict breakthrough.


Figure 1.5 Comparison of AOCM and perlite media for (a) equilibrium isotherm capacity, (b) non-equilibrium kinetics for TDP of 0.5 [mg/L], (c) breakthrough and exhaustion behavior for TDP of 0.5 [mg/L], and (d) runoff volume treated for a $70 \mathrm{~L}$ bed volume of media and TDP of 0.5 $[\mathrm{mg} / \mathrm{L}]$. 
The table at the lower right-hand corner of Figure 1.5 indicates the runoff volume treated under breakthrough and exhaustion conditions for empty bed contact times (EBCT) of 1.25 and 2.0 minutes for a media bed volume of $70 \mathrm{~L}$. The volume of runoff treated at an influent TDP of $0.5 \mathrm{mg} / \mathrm{L}$ at breakthrough and exhaustion for the two EBCT (not at equilibrium, but at typical high rate contact times) were compared to capacity determined by equilibrium isotherms. As expected, non-equilibrium capacities were lower than equilibrium capacities. Under both EBCT conditions and under equilibrium conditions, the AOCM capacity was more than two orders of magnitude higher than perlite.

\subsection{Conclusions}

Our modeling capabilities continue to improve. Yet, a general lack of sufficient and reliable PSD data and algorithms for constitutive phenomena makes the accurate calibration of such models difficult. Proper sampling and analysis techniques are required to accurately determine (i) particle gradation, (ii) pollutant mass and loading relationships to particles, and (iii) distribution of pollutants across particle gradations. Our review of previous studies found that many of the current methods and techniques used for sample collection and analysis could cause a significant under- or overestimation of gradations and loadings of suspended sediments and associated pollutants. Those misrepresentations appear to be caused by not measuring fine and coarse fractions during sampling and/or analytical procedures. To develop accurate and quantifiable TMDLs for selection of BMPs for regulatory purposes, accounting for a full spectrum of PSDs and sediment concentrations transported in stormwater is critical. Such knowledge also helps prevent undersized treatment measures and more frequent maintenance requirements. In addition, many stormwater quality and quantity models using an equation based mainly on empirical data have to be calibrated in order to produce reliable quality results. In fact, quality predictions might not be very useful without local defensible data for calibration and validation.

This study examined event-based PSDs for particulate matter transported in runoff from a $1088-\mathrm{m}^{2}$ source area paved urban watershed during storm events. Storm events were examined and the full spectrum of particle gradation in the entire volume of runoff from each event was monitored. The results in this study indicate that urban runoff transports a very wide size range of particulate matters from micron size to larger than 10,000. A 
significant variability of PSDs between events for the same catchment area is found. No significant relationship between PSD and hydrologic indices such as storm intensity and previous dry hours was found. While sediment size particles $(>75 \mu \mathrm{m})$ are often misrepresented during sample collection, management and analysis, the mass fraction associated with such particles comprises a major fraction of the total particulate matter for source area watersheds. However, the suspended fraction is more acutely bio-available, more mobile and much more difficult to treat. The coarse fraction is a maintenance problem for conveyance systems and for BMPs and is more labile than the fine fraction for phosphorus, since the phosphorus is bound more physically than chemically to the coarser fractions. Because of the availability of pollutants that are easily leached from the coarse fraction, the coarse fraction should be managed before collection in BMPs where such pollutants can be leached between wet weather events and transported downstream. To address the debate over the role of the entire PM gradation, BMP effluent requirements should not be based on a \% reduction based on mass, but a representative effluent concentration, such as the combination of a representative event-based concentration and representative annual concentration (based on continuous simulation modeling such as in SWMM, combined with representative and defensible third-party monitoring data).

The phosphorus results allow characterization of existing surficial contamination and source area management of loading when considering potential fate and control of phosphorus transported by urban drainage and are distributed across the particulate matter size gradation. Granulometric distribution of particulate-bound phosphorus (PP) shows that PP mass concentration ranges from 1.1 to $3.4[\mathrm{mg} / \mathrm{g}$ ] regardless of hydrograph and exhibits increasing concentration as particle size decreases, by definition. As expected, phosphorus associated with suspended particles $(<25 \mu \mathrm{m})$ comprises a significant portion of PP in mass for all events. However, the analysis for phosphorus also demonstrated that $35 \%$ up to $64 \%$ of the PP mass on an event basis were associated with sediment size particles $(>75 \mu \mathrm{m})$. Such results imply that inaccurate quantification of sediment particles in a stormwater treatment or monitoring program could underestimate phosphorus loading into a receiving water body. Considering the significant quantitative association ( 15 to $50 \%$ of total PP) of phosphorus to suspended particles $(1 \sim 25 \mu \mathrm{m})$, the implementation of BMPs effective in controlling those fine stormwater particles will be needed to reduce PP loadings to downstream receiving water bodies, with required frequent maintenance. We have come to recognize that we cannot operate a WWTP 
without regular maintenance (for example sludge management from primary and secondary clarifiers), our BMPs are no different.

Results for engineered media clearly indicate that stormwater media behavior can be very different for a constituent of interest; in this study, phosphorus. While this study compares two limiting cases, perlite, with no capacity for phosphorus (or metal); and AOCM, a media designed for high phosphorus capacity and uptake, the results clearly illustrate that understanding adsorptive-filtration mechanisms and quantitative media performance is a critical precursor for any media applications. In addition, the ability of a media to retain adsorbed phosphorus between maintenance cycles is critical in storm water systems. In other words, the pollutant should not be leached or desorbed from media under conditions that the media is subjected to in a stormwater BMP. Media systems should provide control and conditioning for media influent and not be applied without primary treatment or possibly secondary treatment that can be quantified. Media applications without such upstream pre-treatment have a long history of documented failure from the wastewater industry. Systems such as engineered cementitious permeable pavement (CPP) that combine hydrologic restoration, filtration and sorptive mechanisms provide combined primary treatment to engineered media applications downstream. Ultimately, a knowledge of the hydrology of treatment mechanisms for particles and phosphorus (or metals); and the interactions between hydrology and geochemistry and the maintenance of such systems are critical to success or failure of these systems.

\section{References}

Allen, T. (2004). Particle size measurement volume 1: Surface area and pore size determination, 5 ed., Chapman \& Hall, New York.

American Public Health Association (APHA). (1998). Standard methods for the examination of water and wastewater, 20th Ed., A.D. Eaton, L.S. Clesceri, and A.E. Greenberg, eds., Water Environment Federation, Washington, D.C.

American Society for Testing and Materials (ASTM). (1993). "Standard practice for dry preparation of soil samples for particle size analysis and determination of soil constants." Annual book of standards, Designation: D 421-85, Vol. 04.08, Philadelphia, 8-9.

Ball, J. E., and Abustan, I. (1995). "An investigation of particle size distribution during storm events from an urban catchment." The Second International Symposium of Urban Stormwater Management, Melbourne, Australia, 531-535. 
Bedient, P. B. and Huber, W. C. (1992). Hydrology and floodplain analysis. Addison WesleyPublishing, Massachusetts.

Characklis, G. W., and Wiesner, M. R. (1997). "Particles, metals, and water quality in runoff from large urban watershed." J. Environ. Eng., 123(8), 753-759.

Dean, C. M.; Sansalone, J. J.; Cartledge, F. K., and Pardue, J. H. (2005). "Influence of hydrology on storm water metal element speciation at the upper end of the urban watershed.” J. Environ. Eng. 131(4), 632-642.

Ellis, J. B., and Revitt, D. M. (1982). "Incidence of heavy metals in street surface sediments: solubility and grain size studies." Water air soil poll., 17, 87-100.

Gjessing, E., Lygren, E., and Anderson, S.(1984). "Acute toxicity and chemical characteristics of moderately polluted runoff from highways." Sci. of the Total Envir., 33, 225-232 .

Jacopin, C., Bertrand-Krajewski, J., and Desbordes, M. (1999). "Characterization and settling of solids in an open, grassed, stormwater sewer network detention basin." Wat. Sci. Tech. 39(2), 135-144.

Legret, M., and Pagotto, C. (1999). "Evaluation of pollutant loadings in the runoff waters from a major rural highway.” Sci. Total Environ., 235, 143-150.

Morton, S. C., Glindemann, D., and Dewards, M. A. (2003). "Phosphates, Phosphites, and Phosphides in Environmental Samples.” Environ. Sci. Technol., 37(6), 11691174.

Muschack, W. (1990). "Pollution of street run-off by traffic and local conditions." Sci. of the Total Envir., 93, 419-431.

Nybakken, J. W. (1998). Marine biology, an ecological approach, 2nd Ed., Harper \& Row, New York.

Rice, K. C. (1999). "Trace-elements concentrations in streambed sediment across the conterminous Unites States.” Environ. Sci. Technol., 33(15), 2499-2504.

Sansalone, J. J., and Tribouillard, T. (1999). "Variation in characteristics of abraded roadway particles as a function of particle size - implications for water quality and drainage, Trans. Res. Rec., 1690, 153-163.

Sansalone, J. J., Koran, J. M., Smithson, J. A., and Buchberger, S. G. (1998). "Physical characteristics of urban roadway solids transported during rain event." J. Environ. Eng., 124(5), 427-440.

Sartor, J.D., and Boyd G.B. (1972). Water pollution aspects of street surface contaminants. EPA-R2-72-081. 236.

Shaheen, D. (1975). Contribution of Urban Roadway Usage to Water Pollution. EPA600/2-75-004.

Sharpin, M. G. (1995). "Stormwater Quality and Urbanisation.” Sharpin MG (ed), Environmental Aspects of Urban Drainage, Proceedings of a Stormwater Industry Association Seminar, Sydney.

Vaze, J., and Chiew, Francis H.S. (2002). "Experimental study of pollutant accumulation on an urban road surface." Urban Water, 4, 379-389.

Viessman, W., and Lewis, L. (1996). Introduction to Hydrology, 4th ed., HarperCollins College Publishers, New York.

Westerlund, C., and Viklander, M. (2006). "Particles and associated metals in road runoff during snowmelt and rainfall." Sci Total Environ., 362(1-3), 143-56. 